\title{
Understanding destination image: the case of Linz, European capital of culture, 2009
}

\author{
Elitza lordanova ${ }^{1}$
}

Received: 27/02/2014

1 Buckinghamshire New University, High Wycombe Campus, Queen Alexandra Road, Buckinghamshire, HP112JZ, UK, +44(0)1494522141 ext. 4127, e-mail: Elitza.lordanova@bucks.ac.uk

Supervisors: Dr Eugenia Wickens and Dr Ali Bakir

Institution awarding the Ph. D. Degree: Brunel University

Date of defence: 01 February 2013

C) 2014 International University College. All rights reserved

Citation: Iordanova, E. (2014). Understanding destination image: the case of Linz, European capital of culture, 2009. Doctoral Dissertation Summary. European Journal of Tourism Research 8, pp. 157161

\section{Goal and objectives of the dissertation Goal}

To explore the image of Linz (Austria) as a tourist destination in the context of the European Capital of Culture Event (ECOC) 2009 from its visitors' perspective.

\section{Objectives}

- To discover Linz's cognitive and affective destination image components;

- To identify Linz's destination image determinants (e.g. socio-demographic characteristics, familiarity, information sources, motivation, trip characteristics) and their significance in the process of Linz's destination image formation;

- To analyse the process of Linz's destination image formation, and

- To examine the importance of the European Capital of Culture Event in the process of Linz's destination image formation.

\section{Methodology}

The research used in this thesis was a sequential one - with second quantitative, phase building on a qualitative and explorative first phase. The first phase represented an exploration of Linz's image from 74 potential visitors by using free elicitation technique. Afterwards, the findings from the qualitative phase were used to construct a questionnaire, which was then utilised to collect data from 400 visitors of Linz during the ECOC in August, 2009. The collected data was analysed by using ANOVAs, MANOVAs, t-tests and factor analysis.

\section{Results}

Throughout the data analysis it became evident that the respondents' socio-demographic characteristics and Linz's "a priori" and "on situ" images are interrelated, nevertheless, some of the characteristics were more influential than 
others. Nationality was found to affect Linz's cognitive "a priori" image only, but both cognitive and affective "on situ" images. It was also unveiled that the smaller the distance, the more negative the image, since Austrians were found to have more negative image of Linz than the Internationals. Gender did not appear to be a major determinant in the process of Linz's "a priori" and "on situ" images development since gender as an intervening variable was found to affect only one of the cognitive "a priori" elements, but none of the affective ones.

The research findings suggested only a moderate relationship between education and Linz's image as it was found to affect only one of Linz's "a priori" cognitive and affective image components. Respondents' age was found to be of some significance for Linz's cognitive image domain only. Respondents' professional status appeared to have significant impact over one cognitive and one affective dimension of Linz's "a priori" image. Also, the overall results signify that there are significant differences between first time visitors and repeat visitors, and a subsequent strong positive relationship between previous experience with Linz and its associated "a priori" image.

Different types of information sources was also found to influence not only Linz's "a priori", but also its "on situ" cognitive and affective image dimensions, however, with different intensity. Information acquired about a destination based on previous travel to the area seemed to be one of the most influential information sources over Linz's "a priori" and "on situ" images as it affected a significant number of both cognitive and affective image components. With respect to the secondary information sources, it should be stressed that the induced sources represented by the official website of Linz09, brochures and tour operators' advice had a significant influence over some of the cognitive and affective "a priori" and "on situ" image dimensions of Linz, whereas travel agents/intermediaries' advice proved to be the only one induced source which did not display any significant relationship with Linz's image. The organic and autonomous information sources (movies, news articles, reports, etc.) also influence significantly a few cognitive, mainly "a priori" Linz's image dimensions.

It also became evident that motivations impact not only the affective image components, as the literature suggests, but also the cognitive image components. Besides, it was also unveiled that motivations penetrate to the image of a place people have while visiting it, and therefore, affect destinations' "on situ" images which is a rather neglected area in the tourism literature. There is a positive relationship between the duration of a stay and visitors' level of engagement and Linz's image - the longer the stay/the higher the level of visitors' engagement with the destination, the better the image. The data analysis implied that people with more positive image of Linz are more likely to revisit or recommend the place.

Linz09 appears to have been an important event to Linz and to have significantly boosted its image. $60 \%$ of the respondents experienced changes in their perceptions of Linz after participating at different events part of Linz09.

\section{Theoretical conclusions}

Despite the numerous studies and models on destination image formation, their main focus is on analysing the "pre-travel" phase of destination image formation and the relationship between the post-travel image travellers' behavioural intentions. Nonetheless, one could argue that the formation of a destination image does not discontinue once travellers' begin their actual experience, but rather goes through a "modification" or "on-site" stage, which in turn, affects the post-travel evaluation and image, and subsequently the intentions to recommend or re-visit the place. The conceptual model that emerged from this research points out the "on site" destination image and suggests that better understanding of its formation is needed, since as it appeared from the overall data analysis, factors forming the "a priori" image of Linz, penetrate to its "on site" image and significantly affect it as well. This stage was also found to be of crucial importance for further destination visits or recommendations. This model also explicitly shows the possible effect of events on destination images and the possible relationship between duration of the stay in 
Linz, "level of engagement", behavioural intentions and cognitive and affective image dimensions.

\section{Practical application of the dissertation}

This research points out the importance of nationality as an image determinant, and therefore, the need to develop different promotional campaigns based on both cognitive-based attributes of Linz and their affective evaluation for different target markets. Previous destination experience was also found to significantly affect Linz's cognitive and affective "pre-travel" image dimensions and the "on site" image variations, indicating the importance of trying to deliver consistent positive experience with the destination. It was also found out that all autonomous and organic information sources influenced Linz's "a priori" "Blemish" dimension (including Hitler's heritage and the steel industry) and since these information sources are out of Linz promoters' "jurisdiction" and influence people's knowledge about Linz's dark past and its traces into Linz's present image, induced information sources based marketing campaigns must be more aggressive and pointing directly the positive aspects of Linz's image. It could also be suggested that Linz's authorities need to work more closely with the representatives of magazines, radios and TVs to improve Linz's image, and reinforce its rich cultural life, natural beauties and architecture. Moreover, the lack of influence from travel brochures, tour operators and travel agencies over Linz's image indicates that its destination marketers needs to develop more powerful relationships with these in order to guarantee the success of promotional campaigns. Tourists' motivations shape the "pre-travel" and "on situ" stages of

\section{Model of destination image formation and development}

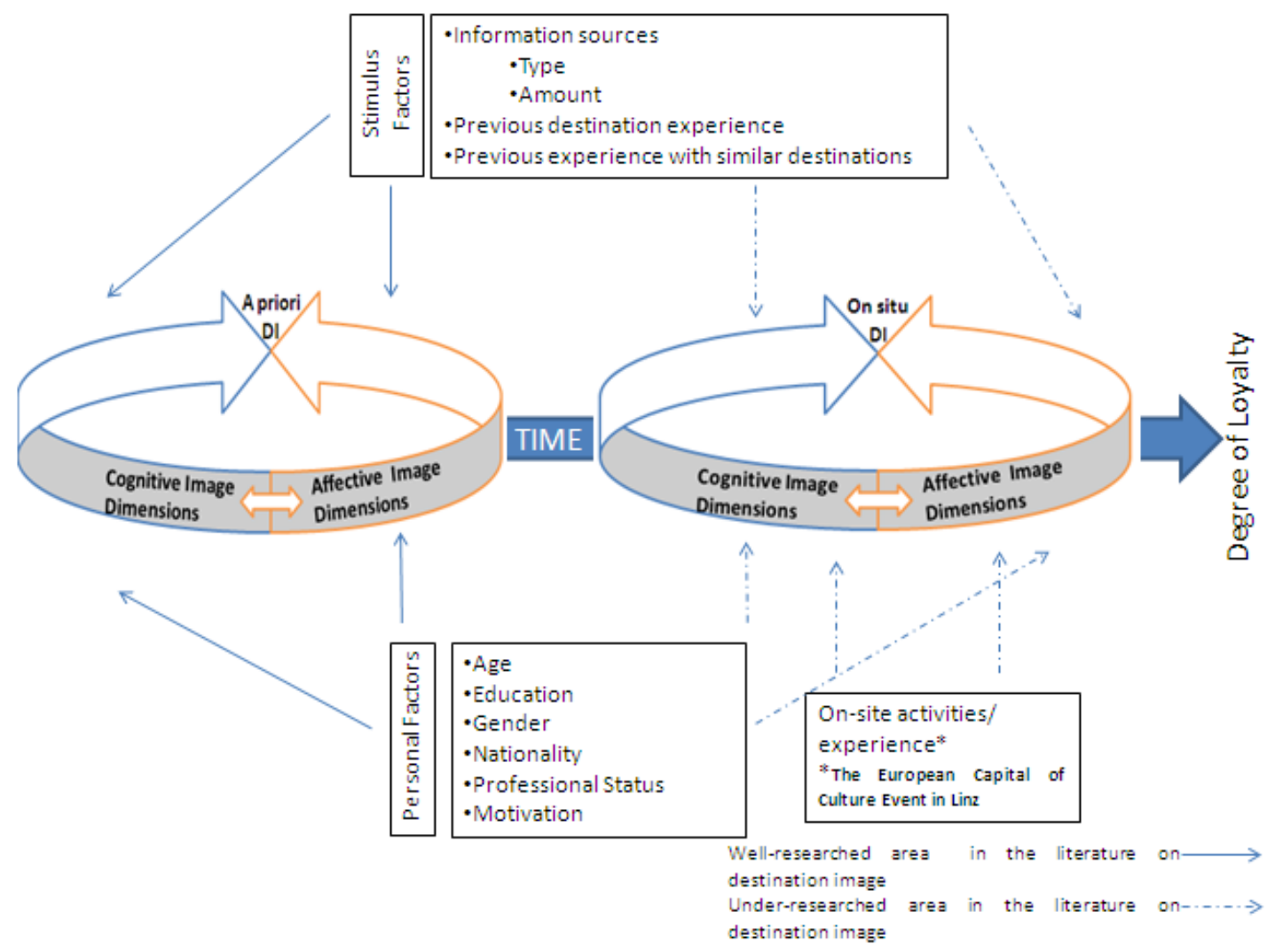

Figure 1. Model of destination image formation and development 
the destination image formation process - not only the "knowledge-based" image, but also the emotional responses towards this image. Therefore, promotional campaigns showing the emotional side of Linz's image and playing with the targeted audience feelings can be used for effective destination differentiation and positioning. Visitors' engagement with Linz also positively affects its "on situ" image, which implicates that holiday packages of a longer duration, accommodation discount for longer stays, free entrances or discounts for attractions and events can be used as strategic instruments for developing a more positive image of Linz.

\section{Content of the dissertation}

Abstract of chapter one:

The intangible nature of tourism product makes tasting it prior to purchase unfeasible, which leads to the use of visuality as a major tool to differentiate destinations from competitors and positively position them in the minds of potential visitors (Baloglu and Mangaloglu, 1999; Echtner and Ritchie, 1993). Still, despite the significant number of work done so far on destination image and its well-recognized importance, there is still no unified definition or theoretical framework on it (Rodrigues et al., 2011; Tasci et al., 2007).

\begin{abstract}
of chapter two:
Destination image is described to be of a "complex, multiple, relativistic and dynamic nature" (Gallarza et al., 2002: 56). Complexity relates to the numerous definitions in the body of literature surrounding destination image and its formation process, and the lack of agreement among researchers as to what constitutes destination image and what types of reciprocal relationships exist among its components.
\end{abstract}

\section{Abstract of chapter three:}

The number of destinations hosting special events and the ECOC in particular as part of, or an enhancement to their tourism products, is growing. Such events have become a major element of destination marketing and are set to accomplish various roles for a particular destination. Most of the research studies, however, focus on the economic impact only of hallmark events.

\section{Abstract of chapter four:}

Linz, the capital of the Province of Upper Austria is situated astride the Danube and its growth of Linz from industrial city to futureoriented cultural and technological city was assured by the completion of a Cultural Development Plan published in 2000. Recently, the mixture of stable local economy, modern technology and culture has become the trademark of Linz (Lewonig, 2007).

\section{Abstract of chapter five:}

Critical evaluation of the existing literature on destination image formation suggested that no single research method could elicit "the multidimensional, complex, relativistic and dynamic" (Gallarza et al., 2002: 56) nature of a destination image. Therefore, two-staged research design (qualitative phase followed by a quantitative phase) was used, which is relatively new to the destination image literature, despite Jenkins' appeal (1999) for a mixed method research in destination image studies due to its multi-dimensional nature.

\section{Abstract of chapter six:}

Throughout the exploratory stage, Linz's cognitive destination image domain was found to have been formed through the symbiosis of Linz Nazi's past and Hitler, steel industry, architecture, well-preserved old town, museums for Modern Art and hallmark cultural events, the River Danube and Postingberg, ancient origin and cultural and historical heritage. Linz was mainly positively described as a pleasurable, enjoyable, beautiful, admirable and modern.

\section{Abstract of chapter seven:}

The data acquired from the closed questions was analysed quantitatively. Descriptive statistics were used to describe and characterize the profile of the respondents. In addition, different statistical tests were used to understand the process of Linz's destination image formation and its determinants, and to explore their interlocking relationships. Content analysis was employed to examine the data collected from open-ended questions.

\section{Abstract of chapter eight:}

The results proved that Linz's image as a tourist destination has gone through a major 
transformation in the respondents' minds where affective image components appeared as more pliable to changes. It was also shown that traditionally accepted "a priori" image determinants such as gender, information sources, motivation, etc. do not only have impact over destinations' "pre-taste", but also strongly affect the way people perceive it once they arrive at the destination. A positive effect of the ECOC over the visitors' image of Linz was reported by the majority of the respondents, suggesting that Linz09 was successful in terms of repositioning in the visitors' minds.

\section{Abstract of chapter nine:}

A profound understanding of destination image is of significant importance for destinations striving to improve and strengthen their positioning in the holiday market. This work addressed relevant, but still under-researched issues that play an important role in the process of destination image formation. Although subject to some methodological limitations, this investigation constitutes a comprehensive analysis of a complex case study which leads to an understanding of how Linz's destination image was formed and developed in the context of the ECOC 2009. It was found that the complexity of destination image formation process and development is related to its multi-layered and dynamic nature and is further shaped by a set of image determinants. A general conceptual model of destination image formation has been formulated, which may be used to inform further studies.

\section{References}

Baloglu, S. \& Mangaloglu, M. (2001). Tourism destination images of Turkey, Egypt,Greece, and Italy as perceived by US-based tour operators and travel agents, Tourism Management, 22: 1-9.

Echtner, C. \& Ritchie, J. (1993). The Measurement of Destination Image: An Empirical Assessment. Journal of Travel Research, 31 (4), 3-13.

Gallarza M., Gil, I., \& Calderon, H. (2002). Destination Image: Towards a Conceptual Framework. Annals of Tourism Research, 29 (1), 56-78.

Jenkins, H. (1999) Understanding and Measuring Tourist Destination Image. International Journal of Tourism Research, 1, 1-15.

Lewonig, J. (2007). Linz expects a New Image. URL:

http://www.culturelive.It/en/vilnius2009/n

ews/news1-newimage (Accessed on 21.05.2009).

Rodrigues, A., Correia, A. \& Kozak, M. (2011). A Multidisciplinary Approach on Destination Image Construct. Tourismos: An International Multidisciplinary Journal of Tourism, 6 (3), 93-110.

Tasci, A., Gartner, W., \& Cavusgil, S. (2007). Conceptualization and operationalization of destination image. Journal of Hospitality and Tourism Research, 31, 194-223. 